embryology inadequate for his purposes. To the undergraduate a book of this nature now ranks more as a reference book on systematic anatomy than as a textbook for daily use. For the postgraduate student studying for a higher surgical qualification, however, it retains its value as an authoritative account of normal human anatomy at a level he is expected to be familiar with. The professional anatomist will also find it invaluable as a ready source for refreshing his knowledge of human topography, though beyond this its value to him as a reference book is not likely to be great.

Centenaries are usually joyous occasions, and one feels one should wish Gray 'many happy returns.' However, it is doubtful if the book in its present form will continue to retain its appeal. As constituted at present it tries to cover too much and attempts to satisfy the requirements of widely different classes of reader. The scope of anatomy is so wide nowadays that no single volume can hope to serve both as a student's textbook, and as a detailed work of reference. The main value of Gray lies in the accuracy of its account of detailed human anatomy at the macroscopic level. The availability of such an account is essential, and it may be that future editors may consider limiting the text to this aspect of the subject, expanding it perhaps to take fuller account of biometrics, growth changes, and functional anatomy.

\section{OPERATIVE SURGERY \\ Volumes 6 and 7}

Edited by Charles Rob, M.C., M.Chir., F.R.C.S., and RODNEY SMITH, M.S., F.R.C.S. London: Butterworth \& Co. Ltd. 1958, f5 ros.

The very extensive range of this work is well demonstrated in this volume which contains sections as diverse as ganglion of the wrist, cancer of the face, and gynaecological operations. It is therefore extremely difficult for one reviewer to comment adequately on the volume.

Familiar subjects are covered as clearly and completely as in previous volumes and the exposition of the unfamiliar subjects is so good as to tempt a general surgeon into unfamiliar fields.

The sections on plastic surgery give a concise account of general principles and specific operations. These sections are comprehensive while avoiding unnecessary detail. The whole volume will be of great value to the general surgeon who must occasionally do some of the more specialised operations.

Volume seven covers the breast and genitourinary subjects. There are excellent descriptions of all the well-established procedures. Many surgeons owe their technique of radical mastectomy to Victor Riddell's writings and will welcome the clear account of the operation which he gives in this volume. Other aspects of breast surgery are well covered, although many surgeons may well disagree with some of the details (as, for example, the rather summary dismissal of circum-areolar incisions by Hedley Atkins). Some would feel too that the more extended radical operation (such as Urban's), while not widely accepted in this country, merits some 3 mention in the present uncertainty of views about $\stackrel{\unrhd}{\complement}$ the treatment of breast carcinoma.

The urological sections of the volume are com- $\vec{F}$ prehensive and well-balanced. This balance is well $\stackrel{5}{\rightarrow}$ demonstrated in the description of operations for 0 hydronephrosis in which complete operative details are given of a number of currently popular oper- $\frac{\bar{\omega}}{\bar{s}}$. ations. There are one or two small but important $\bar{\phi}$ omissions in the urological subjects treated, such as bladder neck obstruction in children. It may well क be that the editors considered such matters of too $\vec{\circ}$ specialized interest for a book primarily intended for general surgeons.

Although more difficult to assess than their predecessors because of their very wide range there 0 is no doubt that these latest volumes will be of 3 . similar outstanding value to both general surgeon $\omega_{\tilde{g}}$ and surgical specialist.

\section{AN INTRODUCTION TO SURGERY}

Edited by David H. PATEY, M.S., F.R.C.S. Pp. $\mathrm{xi}+228$, with 54 diagrams. London. Lloyd Luke Ltd. 1958. Cloth-bound edition r7s. 6d. $\vec{c}$ Paper-bound 9s. 6d.

It is always, in any subject, a matter of dispute exactly where the process of introduction merges into close and serious study. Mr. Patey and his colleagues have tried, with a considerable measure of success, to provide a textbook link which will have definite though limited part in this transition. very necessity underlines the still ill-realised concept of the inter-relation and controlled planning of preclinical and clinical teaching.

The book is based on lectures given to Middlesex junior surgical students, and its three sections- $Q$ General Principles, Method of Examination, and $\overrightarrow{0}$ Practical Procedures follow a rational, easily 3 followed and simply expressed sequence. The first section is the best; the third is marred by a poor allocation of space-very slight rearrangement and economy would have allowed an illustration of $\frac{}{3}$ digital block, and of the commoner finger incisions. There are about eight blank pages-and two are 3 utilised to show circumcision!

The dangers of intra-muscular injection could $\mathrm{O}$ be emphasized, and expansion would be welcome on Hilton's method and the use of the endotrachealo tube. Surely, too, local anaesthesia facilitates the $\triangle$ tapping of a hydrocele! Though disguised in a을. 'trivial' situation, regrettably the 'warm drink appears in the section on first aid, without any warnings.

The glossary does less than justice to the student intelligence but there is a useful little appendix of $\omega$ normal values. A sad reflection on present-daye costs of printing and book production is that theo price difference (8s.) represents a stiff cloth binding. I would urge the publishers to abandon the library? edition-the text is excellent, but the book has a 0 transitory value greater therefore in lightweight ando cheaper format. Thus, it can be thoroughly recom- $-\overrightarrow{\mathbb{D}}$ 
mended, since its woven texture will survive long enough to provide a matrix for replacement by the standard textbook.

\section{DISEASES OF CHILDREN IN THE SUB- TROPICS AND TROPICS}

Edited by H. C. Trowell, O.B.E., M.D., F.R.C.P., and D. B. JellifFE, M.D., M.R.C.P., D.C.H., D.T.M. \& H. Pp. xvi+919. London: Edward Arnold Ltd. I958. 105s.

At last an attempt has been made to write a general book on diseases of children for use by medical students and doctors who live in the tropics - the attempt has been successful and this book can be recommended wholeheartedly.

The 75 contributors are drawn from such widely scattered places that the doctors in no tropical area can possibly feel that the authors of the book are entirely unfamiliar with their special local problems.

In every chapter there is a welcome and practical attitude to the prevention of disease. This is brilliantly exemplified by the illustrations in the section on liver fluke infection: on one page is a picture of a child defaecating into the water from a boat while the father fishes, and on the opposite page a picture of a family having a meal of raw fish at home.

Will the examiners for the Diploma in Child Health take note of this book ? If they do, perhaps the tendency to turn the minds of our visitors from the tropics even further towards an undue concern with rare diseases will be lessened.

The book is worth every one of the hundred and five shillings, but at a third of the price it would have a greatly increased sale and thus might be even more profitable to the publishers. T.S.

\section{NEOMYCIN: ITS NATURE AND PRACTICAL APPLICATION}

Edited by Selman A. Waksman. Pp. $x+412$. London: Baillière, Tindall \& Cox Ltd. 1958. 4os.

While neomycin is not one of the major antibiotics its relative importance, as well as that of other minor antibiotics, has increased as the problem of dealing with resistant organisms has become more difficult. We require to know a good deal about those agents which may enable us to rest the more widely used preparations or to conserve them for the most serious conditions.

Neomycin was originally considered as a tuberculocidal drug, but its severe toxic effects on hearing and on the kidney excluded it from parenteral use. Reconsideration of its properties have allowed it to be used occasionally. Probably one of the important features of neomycin, both from the point of view of medicine and of experimental bacteriology, is that it is in the bactericidal group of agents compatible with penicillin and streptomycin.
This book, edited by the great authority on the drug, gives all the available information on its production, chemistry and actions. W.H.H.

\section{RADIOISOTOPE TECHNIQUES IN CLINICAL RESEARCH AND DIAGNOSIS}

By N. Veall, B.Sc., F.Inst.P., and H. Vetter, M.D. Pp. xii +4I7. London: Butterworth \& Co. Ltd. I 958 . 5os.

This book presents in a very practicable form the considerable experience of the authors in the field indicated in the title. The 21 chapters fall naturally into two parts, of which the first gives a general treatment of the subject and the second deals with particular techniques in detail, concluding with a short chapter on isotope therapy.

After an account of the general principles underlying the use of radioactive isotopes, the authors give a full discussion of the apparatus available and deal with the choice of equipment, its calibration and use with different isotopes. This discussion, together with the chapters on the estimation of radiation dosage to patients and workers, would be particularly useful to clinicians without specialized training in physics who are interested in setting up an isotopes laboratory. This part of the book also contains an account of general isotope procedures and techniques, illustrated with some specific examples.

The second part of the book includes several chapters on blood studies and chapters on electrolyte studies, thyroid tests, fat and protein studies and the localization and diagnosis of malignant tumours. Thyroid tests are less fully treated than is customary in textbooks on clinical radioisotopes, but this is no great disadvantage as the subject is well covered elsewhere. The authors' account of clinical matters could be readily understood by a physicist new to this work and it provides an adequate physiological background to enable him to apply his own specialized knowledge to the clinical field.

The plan of the book sometimes leads to the same subject being treated several times from different points of view and it is therefore rather more suitable for reading as a whole than for quick reference on specific points. A good bibliography at the end of each chapter will enable those with specialized interests to pursue them further.

\section{THE KIDNEY}

\section{An Outline of Normal and Abnormal Structure and Function}

By H. DE WARDENER, M.B.E., M.D., F.R.C.P. Pp. viii +338 , illustrated. London: J. \& A. Churchill Ltd. 1958. $45 \mathrm{~s}$.

Knowledge about the kidney in health and disease has increased greatly during the past two decades. British investigators have made important contributions in this field and Dr. de Wardener 